\title{
MASTER
}

\section{Space-Dependent Thermal Stability of Reacting Tokamak Plasmas}

W. A. Houlberg

R. W. Conn 


\section{DISCLAIMER}

This report was prepared as an account of work sponsored by an agency of the United States Government. Neither the United States Government nor any agency Thereof, nor any of their employees, makes any warranty, express or implied, or assumes any legal liability or responsibility for the accuracy, completeness, or usefulness of any information, apparatus, product, or process disclosed, or represents that its use would not infringe privately owned rights. Reference herein to any specific commercial product, process, or service by trade name, trademark, manufacturer, or otherwise does not necessarily constitute or imply its endorsement, recommendation, or favoring by the United States Government or any agency thereof. The views and opinions of authors expressed herein do not necessarily state or reflect those of the United States Government or any agency thereof. 


\section{DISCLAIMER}

Portions of this document may be illegible in electronic image products. Images are produced from the best available original document. 
Printed in the United States of America. Available from National Technical Information Service

U.S. Department of C'ommerce

5285 Port Royal Road, Springfield, Virginia 22161

Price: Printed Copy $\$ 4.50$; Microfiche $\$ 3.00$

This report was prepared as an account of work sponsored by an agency of the United States Government. Neither the United States Government nor any agency thereof, nor any of their employees, contractors, subcontractors, or their employees, makes any warranty, express or implied, nor assumes any legal liability or responsibility for any third party's use or the results of such use of any information, apparatus, product or process disclosed in this report, nor represents that its use by such third party would not infringe privately owned rights. 
Contract No. W-7405-eng-26

FUSION ENERGY DIVISION

SPACE-DEPENDENT THERMAL STABILITY

OF REACTING TOKAMAK PLASMAS

\author{
W. A. Houlberg \\ Department of Nuclear Engineering \\ University of Wisconsin, Madison, Wisconsin \\ and \\ Oak Ridge National Laboratory \\ and \\ R. W. Conn \\ Department of Nuclear Engineering \\ University of Wisconsin, Madison, Wisconsin
}

Date Pub1ished - June, 1978

Prepared by the OAK RIDGE NATIONAL LABORATORY

Oak Ridge, Tennessee 37830 operated by UNION CARBIDE CORPORATION

for the DEPARTMENT OF ENERGY
This report was preporice

This report was prepared as an account of work United States nor the Unites Government. Neither the Energy, nor any of their ed States Department of contiacturs, subcontrair employees, nor any of their any warranty, express or implied, employees, makes liability or responsibit implied, or assumes any legal or usefulness of any infor the accuracy, completeness process diecloseu, ur infirtnge proately, of represents that its use would not infringe pnvately owned rights. 
THIS PAGE

\section{WAS INTENTIONALLY \\ LEFT BLANK}


CONTENTS

ABSTRACT . . . . . . . . . . . . . . . . . . . . v v

1. INTRODUCTION . . . . . . . . . . . . . . . . . . 1

2. THE FLUID MODEL . . . . . . . . . . . . . . . . . . 3

3. THERMAL STABILITY ANALYSIS USING A ONE-DIMENSIONAL,

SPACE-TIME TRANSPORT MODEL . . . . . . . . . . . . . . 6

3.1 ANALYSIS OF A TWO-COMPONENT BEAM-DRIVEN PLASMA . . . . . 7

3.2 ANALYSIS OF AN IGNITED PLASMA . . . . . . . . . . . . 10

4. SUMMARY . . . . . . . . . . . . . . . . . 15

ACKNOWLEDGMENTS . . . . . . . . . . . . . . . . 16

REFERENCES .......................... . . 20 
THIS PAGE

\section{WAS INTENTIONALLY \\ LEFT BLANK}


ABSTRACT

A technique is presented for the analysis of thermal stability in reacting tokamak plasmas using a one-dimensional, time-dependent fluid transport model. Application is made to the analysis of density related thermal instabilities in a neutral beam-driven, two-component plasma (TETR) and a conceptual reactor size ignited plasma (UWMAK-III). A density-driven thermal instability can exist when the particle confinement varies as $\tau_{p} \propto n$. This condition is satisfied by the trapped ion mode diffusion model and an empirical model. A time delay in the heating due to finite alpha thermalization does not significantly alter the character of the instability at normal plasma densities. A linear feedback response for the particle source is found to provide a stabilized equilibrium in all cases. Strong radial variation of the transport and physical properties of the plasma are not found to introduce radial-dependent feedback requirements. Feedback on the average density is sufficient for stabilization with moderate response times. 


\section{INTRODUCTION}

The thermal stability of reacting plasmas has been examined in several papers published in recent years [1-7]. Stacey [1] pointed out that coupling between the particle and energy balance equations can give rise to growing density and temperature oscillations when the transport in reacting tokamak plasmas is assumed to be caused by the dissipative trapped ion mode [8]. Most earlier work [2-7] had been primarily concerned with demonstrating an instability in temperature at the ignition point and the existence of a stable equilibrium at a higher temperature with global analyses'[2-6] or with a one-dimensional (radial) treatment [7]. As noted in Ref. [7], a time-dependent treatment can only reach a stable equilibrium or an equilibrium stabilized by feedback mechanisms.

The results of this work illustrate that a density-driven thermal instability can arise with certain types of diffusion models if the particle source is decoupled from the particle diffusion losses. A type of automatic particle source feedback mechanism operates in most currently operating tokamaks, in which a significant number of particles lost from the plasma are neutralized at the limiter and wall and return to the plasma. However, under divertor operation, strong gettering (or pumping of the particles), and a separate particle fueling scheme, a densitydriven thermal instability can arise when the particle confinement time varies as $\tau_{p} \sim n$, in which case the particle loss rate, $n / \tau_{p}$, becomes density-independent. The temperature dependence of the particle confinement time then determines stability, and a strong coupling between the particle and energy balance equations arises. The dissipative trapped ion mode, in which $D_{1} \sim 1 / \nu_{\text {ei }}$, or other anomalous loss mechanisms in which 
$D_{\perp} \sim 1 / n$, can produce thermally unstable equilibria at higher temperatures than the ignition point. The global analysis of Stacey [1] illustrated that this type of instability could arise with the trapped ion mode, but he suggested further analysis to determine whether spatial dependence and MHD effects have a strong influence.

Many one-dimensional, time-dependent fluid transport computer simulation codes have been developed in recent years for the analysis of tokamak plasmas using a variety of models for the transport and other physical processes $[9,10]$. Because of their capability for a detailed treatment of radially dependent physical processes such as radiation, ohmic and neutral beam heating, cold neutral particle sources, and spatially dependent diffusion and conduction models, these codes can be used to great advantage in analyzing thermal stability. Initial investigations have also been made to couple a two-dimensional MHD equilibrium analysis to a one-dimensional, time-dependent fluid transport modèl tó give a more complete treatment of plasma behavior [11].

The analysis in this paper uses a one-dimensional, time-dependent model for the particle and energy balance equations discussed in Section 2. The computer program WHIST is used to solve the equations using particle and energy conserving difference methods on a nonuniform spatial grid and a variable implicit time treatment which is very stable against numerical oscillations [12]. The numerical methods employed help ensure that any instabilities found are physical and not numerically introduced. Feedback on the particle source intensity is used to maintain the density at a desired level. The feedback can then be turned off and the particle source maintained constant to determine whether the feedback is responsible 
for the stability of the solution. This feedback technique is therefore specifically applicable to thermal instabilities which rely on density variation for their growth. The analysis presented here may also be extended to other types of instabilities and feedback models.

The stability analysis is applied in Section 3 to a neutral beamdriven Tokamak Engineering Test Reactor (TETR) [13] and a conceptual tokamak power reactor, UWMAK-III [14]. A trapped particle microinstability model dominated by the trapped ion mode and an anomalous model where $D_{1} \sim 1 / \mathrm{n}$ suggested by Alcator results [15] are considered for the transport. Since finite alpha thermalization time represents a delay in the coupling between the particle and energy balance equations, this effect is included in the analysis.

\section{THE FLUID MODEL}

The one-dimensional fluid particle and energy balance equations are given by

$$
\begin{aligned}
& \frac{\partial n_{i}}{\partial t}=-\frac{1}{r} \frac{\partial}{\partial r}\left(r \Gamma_{i}\right)+S_{p}(r, t)-2\left[S_{D T}(r, t)+S_{b p}(r, t)\right] \\
& \frac{\partial}{\partial t}\left(\frac{3}{2} n_{e} k_{e}\right)=W_{\alpha e}(r, t)-\frac{1}{r} \frac{\partial}{\partial r}\left[r\left(Q_{e}+\frac{3}{2} k T_{e} \Gamma_{e}\right)\right]-Q_{e i} \\
&-P_{r a d}+P_{o h m}+P_{I N J}^{e} \\
& \frac{\partial}{\partial t}\left(\frac{3}{2} n_{i} k T_{i}\right)=W_{\alpha 1}(r, t)-\frac{1}{r} \frac{\partial}{\partial r}\left[r\left(Q_{i}+\frac{3}{2} k T_{i} \Gamma_{i}\right)\right]+Q_{e i} \\
&-P_{c x}+P_{I N J}^{i}
\end{aligned}
$$


where

$$
\begin{aligned}
\mathrm{n}_{e}, \mathrm{n}_{i} & =\text { electron and ion densities } \\
\mathrm{T}_{e}, \mathrm{~T}_{i}= & \text { electron and ion temperatures } \\
\mathrm{W}_{\alpha \mathrm{e}}, \mathrm{W}_{\alpha i}= & \text { energy from fusion alphas to electron and ion fluids } \\
\mathrm{Q}_{\mathrm{ei}}= & \text { electron-ion rethermalization term } \\
\mathrm{P}_{\mathrm{rad}}= & \text { bremsstrahlung, line, recombination, and synchrotron } \\
& \text { radiation losses } \\
\mathrm{P}_{\mathrm{cx}}= & \text { charge-exchange energy loss } \\
\mathrm{S}_{\mathrm{p}}= & \text { particle source rate due to neutral beam injection, } \\
& \text { pellets, ionization of neutrals, etc. } \\
\mathrm{S}_{\mathrm{DT}}= & \text { rate of Maxwellian } \mathrm{D}-\mathrm{T} \text { fusions } \\
\mathrm{S}_{\mathrm{bp}}= & \text { rate of } \mathrm{D}-\mathrm{T} \text { fusions from collisions of energetic beam } \\
\Gamma_{e}, \Gamma_{i}= & \text { electron and ion particle fluxes } \\
Q_{e}, Q_{1}= & \text { electron and ion energy conduction }
\end{aligned}
$$

The rate of energy transfer from fast alphas to the background electrons and ions can be expressed as

$W_{\alpha j}(r, t)=\int_{-\infty}^{t} F_{\alpha j}\left(r, t ; t^{\prime}\right)\left[S_{D T}\left(r, t^{\prime}\right)+S_{b F}\left(r, t^{\prime}\right)\right] d t^{\prime}$

where it is assumed that the alphas thermalize over a finite period of time but do not diffuse radially while thermalizing. $F_{\alpha j}\left(r, t ; t^{\prime}\right)$ represents the rate of energy transfer to background plasma specie $j$ from fusion alphas born at time $t^{\prime}$. In general, particles born at time $t^{\prime}$ will have a distribution of energies at time $t$. However, a simple approximation 
to the Coulomb collisional relaxation rate can be made which neglects scattering about the mean energy, and a one-to-one correspondence between energy and time is found [16].

$F_{\alpha j}\left(r, t ; t^{\prime}\right)=F_{\alpha j}\left[E_{\alpha}\left(r, t ; t^{\prime}\right), n_{e}(r, t), T_{e}(r, t)\right]$

$E_{\alpha}\left(r, t ; t^{\prime}\right)=E_{\alpha o}-\int_{t^{\prime}}^{t} \sum_{j} F_{\alpha j}\left(r, t^{\prime} ; t^{\prime}\right) d t^{\prime}$

$F_{\alpha i}\left(r, t ; t^{\prime}\right)=-\frac{2}{3 \tau(r, t)} \frac{E_{c}(r, t)^{3 / 2}}{E_{\alpha}\left(r, t ; t^{\circ}\right)^{1 / 2}}$

$F_{\alpha e}\left(r, t ; t^{\prime}\right)=-\frac{2}{3 \tau(r, t)} E_{\alpha}\left(r, t ; t^{\prime}\right)$

$E_{c}(r, t)=\frac{59.2}{A_{i}^{3 / 2}} T_{e}(r, t)$

$\tau(r, t)=3.92 \times 10^{11} \frac{T_{e}(r, t)^{3 / 2}}{n_{e}(r, t)}$

where $A_{i}$ is the mass of the plasma ions and all units are in $\mathrm{cm}, \mathrm{keV}$, and s. Equation (8) is used to calculate the new energy at time $t$ of alpha particles horn at time $t^{\prime}$. The new energy is calculated using local values for the thermalization rates given by Eqs. (9-12). The rate of energy deposition is calculated from Eq. (4).

For the purposes of this study, impurities are neglected so that radiation is limited to normal bremsstrahlung and synchrotron emission. Ohmic heating is included but represents a minor contribution to the total energy source. The toroidal current profile is assumed to be parabolic and constant in time to simplify the analysis. Current diffusion can 
easily be included, but the time to reach an equilibrium distribution becomes very long because of the high plasma conductivity.

A pencil beam model is used to determine the neutral beam deposition profile [17]. Classical Coulomb thermalization leads to an approximate evaluation of beam/plasma fusions [18]. In the cases analyzed here, the beam only provides a small portion of the required fuel. The remainder of the particle source is made up with a cold component, $S_{p}$, with either a centrally peaked or a uniform deposition profile. The total plasma density is maintained constant via a linear feedback mechanism on the cold particle source amplitude with a feedback response time denoted $\tau_{g}$. A diagonal model is used for the particle and energy transport of the form

$\Gamma=-\mathrm{D} \frac{\partial \mathrm{n}}{\partial \mathrm{r}}$

$Q_{e, i}=-x_{e, i} \frac{\partial \mathrm{T}}{e, i}$

A multiregime model for the trapped particle transport coefficients is used which is very similar to that given in Ref. [10]. An alternate empirical model suggested by experimental results [15] is used in some of the cases: $D \sim x_{e} / 5 \sim 1 / n$ and $x_{1}$ is given by the neoclassical expressions [19].

3. THERMAL STABILITY ANALYSIS USING A ONE-DIMENSIONAL, SPACE-TIME TRANSPORT MODEL

Thermal stability in TETR [13] and UWMAK-III [14] is examined here using the one-dimensional, space-time transport model for the density and 
the electron and ion energy fluid equations outlined in Section 2. The procedure used to determine thermal stability is as follows. First, particle source feedback is included and a density-stabilized equilibrium is reached at the desired average plasma density. Second, feedback is turned off just prior to reaching equilibrium; this effectively introduces perturbations in the source intensity, the density, and the temperatures from the stabilized equilibrium values. The profiles are then allowed to evolve in time until a second equilibrium is reached or the plasma quenches. If a second equilibrium is reached which is close to the equilibrium found prior to turning off the feedback, the plasma is considered thermally stable against density, temperature, and source perturbations. If not, the dominant mechanisms for the unstable behavior can be determined from the time evolution of the plasma.

\subsection{ANALYSIS OF A TWO-COMPONENT BEAM-DRIVEN PLASMA}

Several "clean" plasma cases are examined for TETR (parameters given in Table I) in which there are no impurities and no neutral gas recycle. A multiregime model for plasma transport is used in which the trapped ion mode is dominant over most of the plasma radius. In Figs 1 and 2 the time history of the average density and ion temperature is plotted for two different source profiles. In the first case (Fig. 1) the source profile is linearly decreasing in radius, while in the second case (Fig. 2) the source profile is flat. A source response time of $\tau_{\mathrm{s}}=4 \mathrm{~ms}$ gives stabilized equilibria in both cases at an average density of $7.5 \times 10^{13}$ $\mathrm{cm}^{-3}$ with particle confinement times of $\tau_{\text {po }}=37 \mathrm{~ms}$ and $27 \mathrm{~ms}$, respectively. 
When the source feedback is turned off at $200 \mathrm{~ms}$, the plasma relaxes to a second equilibrium.

From the results in Figs 1 and 2, it can be concluded that the plasma is marginally stable. Table II shows that when the source feedback is turned off at $200 \mathrm{~ms}$, all the global plasma parameters are within a few percent of the equilibrium values for both cases. The new equilibrium values of the average density are much lower, indicating the sensitivity to the source strength. I'he average temperature rises as the density drops because the constant injection power from the beam heats fewer particles. Particle source perturbations of about $2 \%$ have led to roughly $10 \%$ changes in the equilibrium density. From a global analysis, the diffusion loss is $\mathrm{n} / \tau_{\mathrm{p}}$ and $\tau_{\mathrm{p}} \sim \mathrm{n}$ for the trapped ion mode which dominates the diffusion. The temperature dependence of $\tau_{p}$ then dictates the new equilibrium density when the particle source is perturbed.

The fusion alphas are assumed to thermalize instantaneously in the cases discussed so far, but it is clear that the finite alpha thermalization time will introduce a delay in the heating rate of ions and electrons by alpha particles [20]. The rate of production of alphas is insensitive to the plasma density in a neutral beam-driven, two-component device 1ike TETR but is very sensitive to the density in a 50-50 D-T plasma. The alpha thermalization time is density-dependent, which Introduces an additional effect in the coupling of the fusion energy source to the plasma.

Figures 3 and 4 show the effects of finite alpha thermalization on the time history of the average plasma density and temperature. The cases are the same as those shown in Figs 1 and 2 except for the finite 
thermalization time. When the feedback is turned off, the plasma relaxes to a stable thermal equilibrium with the same qualitative behavior as before. At $200 \mathrm{~ms}$, however, the plasma is further from equilibrium than in the previous cases due to the slower heating rates of the alphas. This accounts for the greater difference in densities at the second equilibrium. When the feedback is turned off at $300 \mathrm{~ms}$ the plasma is closer to equilibrium and the drift in density is reduced.

An alternate model of anomalous transport based on an empirical fit to Alcator results [15] is given by $x_{e}=5 \mathrm{D}=\mathrm{C} / \mathrm{n}$. The value $\mathrm{C}=$ $2 \times 10^{18}$ (in units of $\mathrm{cm}$ and $\mathrm{s}$ ) gives roughly the same stabilized thermal equilibria found in the earlier cases, i.e., about the same energy confinement time and temperatures for the case in Fig. 2. The density equation is completely decoupled from the energy balance equations with this model since the diffusion coefficient is independent of temperature. Small perturbations in the particle source lead to a linear drift in density away from equilibrium. The characteristic time for this drift can be simply approximated as $\tau_{\text {eff }}$ :

$\frac{1}{n_{0}} \frac{d \delta n}{d t}=\frac{{ }_{\tau_{p o} S_{p o}}}{S_{p}}=\frac{1}{\tau_{\text {eff }}}$ At the stabilized equilibrium $\mathrm{n}_{\mathrm{o}}=7.5 \times 10^{13} \mathrm{~cm}^{-3}, \mathrm{~s}_{\mathrm{po}}=1.678 \times 10^{15}$ $\mathrm{cm}^{-3} \mathrm{~s}^{-1}$, which gives $\tau_{\text {po }}=44.7 \mathrm{~ms}$. The perturbed source is $\mathrm{s}_{\mathrm{p}}=$ $1.672 \times 10^{15} \mathrm{~cm}^{-3} \mathrm{~s}^{-1}(0.36 \%$ decrease $)$ when the feedback is turned off at $0.75 \mathrm{~s}$, which leads to an estimate of $\tau_{\text {eff }}=12.5 \mathrm{~s}$. From the slope of the density curve in Fig. 5, $\tau_{\text {eff }}=\left|1 / \mathrm{n}_{\mathrm{o}} \mathrm{d} \delta \mathrm{n} / \mathrm{dt}\right|^{-1}=12.5 \mathrm{~s}$, which 
is in perfect agreement. The shape of the density profile does not change during the course of evolution, so the global estimate is valid.

\subsection{ANALYSIS OF AN IGNITED PLASMA}

UWMAK-III [14] is an ignited reactor size plasma (parameters are given in Table III) which exhibits a dynamic behavior entirely different from a two-component-driven device like: TETR. Impurities and neutral gas recycle are again neglected. Because of the lack of temperature dejendence in the anomalous $\left(x_{e} \sim 1 / n\right)$ model, the plasma temperature runs away to extremely high values similar to neoclassical results before reaching a stabilized thermal equilibrium. For that reason only the trapped particle model results are presented for UWMAK-III. Several examples are presented here to illustrate the dynamic behavior. The effects of the shape of the particle source profile, the magnitude of the particle source perturbation (determined by when the feedback is turned off), and finite thermalization of the fusion alphas are considered.

The time history of the average density and ion temperature for a centrally peaked particle source is shown in Fig. 6 with instantaneous thermalization of the fusion alphas assumed. A feedback response time of $\tau_{s}=60 \mathrm{~ms}$ gives stabilized equilibria in this and ail subsequent cases. The feedback is turned off at $4.5 \mathrm{~s}$ and the plasma quenches about $2 \mathrm{~s}$ later. When the feedback is turned off at $5.4 \mathrm{~s}$, the plasma is closer to equilibrium and the instability takes longer to develop. Quench occurs about $5 \mathrm{~s}$ later. The equilibrium particle confinement time is $320 \mathrm{~ms}$ in these cases. The dynamic behavior cannot be explained solely in terms of the average parameters, particularly when the oscillations become large. 
Figure 7 shows the time history of the density and electron and ion temperature profiles after the particle source feedback is turned off at $4.5 \mathrm{~s}$. Initially, the temperatures are rising from the heatup phase. The decrease in collisionality increases the diffusion losses [trapped ion mode, $\left.D \propto(d \ln n / d r)^{2} T^{2} / \nu_{e i}, \nu_{e i} \propto n / T^{3 / 2}\right]$ and the density decreases. At about $4.8 \mathrm{~s}$ the decrease in density has reduced the fusion alpha production and the temperatures begin to drop. From 5.0 to $5.8 \mathrm{~s}$ the decrease in temperature reduces the diffusion losses because of the dominance by the trapped ion mode. This reduction in losses begins to flatten the density profile (Fig. 7a), which further reduces the losses. At about $5.8 \mathrm{~s}$ the increase in density overcomes the decrease in temperature to increase the fusion alpha production $\propto_{n}{ }^{2}\langle\sigma v\rangle$. Note that the rise in temperature is fastest near the center of the plasma (Figs $7 \mathrm{~b}$ and $7 \mathrm{c}$ ), where the fusion alpha production is strongly peaked. The rapid rise in temperature increases the diffusion losses, and the density drops sharply from 6.0 to $6.3 \mathrm{~s}$. The fusion alpha production is sharply reduced and the temperatures again decrease. This decreases the diffusion losses and the density recovers. The temperatures have decreased to below the ignition point and the plasma has "quenched."

If the particle source feedback is turned off somewhat later, at $5.4 \mathrm{~s}$, the same basic behavior is exhibited with two important differences. As shown in Fig. 6 the instability takes longer to develop since the plasma is closer to equilibrium (smaller perturbations). The plasma nearly quenches because of the low temperatures and takes longer to recover than it did in the first case (Fig. 6). The density continues to build while the temperatures are $10 \mathrm{w}$ and cause a greater burst in alpha production 
once the temperatures do recover. Figure 8 shows the time-dependent density profile for this case. When the temperature rises, the particle losses increase due to the trapped ion mode scaling, and the density decreases. An increased density gradient also promotes a higher particle loss rate. All these processes reverse after the quench, and the density rapidly increases.

The time history of the average ion density and temperature when the particle source is uniform 1s shown in Fig. 9. The equilibrium particle confinement time is $270 \mathrm{~ms}$ for this model, which also assumes instantaneous thermalization of the fusion alphas. These two cases exhibit behavior similar to the two previous examples. Plasma quench occurs about $2.5 \mathrm{~s}$ after the feedback is turned off. The primary effect of the flat source profile is that the buildup in density in the outer region is accelerated (Fig. 10). This indicates that the thermal instability is intensified when the particle source is increased in the region where the instability first develops. Coupling between the particle source profile and the density profile should be an important effect based on these observations. If the particle source profile flattens or becomes more peaked to the outside as the density profile flattens, the instability could grow more rapidly. Since only the average density is sensed and the feedback is not spatially dependent, the feedback requirements are not very stringent for these cases.

If the fueling source is partly from neutral gas at the plasma edge, while the remainder is from a more centrally peaked source controlled by feedback (such as pellet injection), two major effects on the stability would be expected. Based on a global analysis, the gain requirement on 
the feedback source would be increased because only part of the total source is being used for feedback. Secondly, the contribution from neutral gas is peaked to the outside and is coupled strongly to the density at the plasma edge. Both effects would be expected to make control of the plasma more difficult with the plasma transport model used here. However, if the intensity of the neutral gas source can be increased to the point where the density profile is nearly flat, the domination by the trapped ion mode might be eliminated. This would dramatically affect all of the preceding stability analyses.

Figure 11 shows the effect of finite alpha thermalization on the time history of the average density and electron and ion temperatures. The particle source is spatially uniform, and the feedback is turned off at $6.0 \mathrm{~s}$. The instability develops almost identically to the instantaneous thermalization cases (Fig. 9) until the density becomes very low (after about $8.3 \mathrm{~s}$ on the figure). Until this time the density is high enough in the central region $\left(>10^{14} \mathrm{~cm}^{-3}\right)$. to ensure a short thermalization time for the alphas. At low density, the thermalization time becomes long and the fusion alphas (produced when the density peaked) thermalize over a long period of time $(\sim 1.5 \mathrm{~s})$ and maintain the plasma temperature. During the period of low density, the electron temperature is initially greater than the ion temperature since the high energy alphas are primarily thermalizing on the electrons. As the alphas thermalize, more energy is given to the ions and $\mathrm{T}_{i}>\mathrm{T}_{e}$ at later times. The oscillations in density and temperatures are due to the density dependence of the alpha thermalization time. As $\mathrm{n}$ increases slightly, 
the alphas thermalize more rapidly and raise the temperature. As the temperature increases, the diffusion increases and the density drops.

The time history of the density and electron and ion temperature profiles is shown in Fig. 12. The density profile (Fig. 12a) has a time history similar to that shown in Fig. 10a for instantaneous thermalization except that the low density region is extended in time by the finite alpha thermalization. The electron and ion temperatures initially rise together (Figs $12 b$ and $12 c$ ) with strong peaking at the center from the alphas. Some of the roughness in the time history of the ion temperature profile is due to the coarse time mesh used for the alpha thermalization (every fifth time step).

Diffusion of the alpha particles has been neglected in this analysis but would be important when the thermalization or slowing-down time, ' $\mathrm{SD}$ ' becomes long compared to the alpha particle confinement time, $\tau_{p \alpha}$. The global analysis of Tsuji et al. [20] showed that an energy-independent loss of alpha particles via radial diffusion can significantly reduce the heating by the alphas when $\tau_{\mathrm{SD}}>\tau_{\mathrm{p} \alpha}$. However, two important spatial effects limit the applicability of their global results. The alpha particle birth protile is very strongly peaked at the center of the plasma for centrally peaked density and temperature profiles. If they do diffuse outwardly, the alphas have a relatively long way to travel to the plasma edge and will undoubtedly be degraded in energy. The diffusion loss would be more peaked to the lower end of the energy spectrum. Secondly, the collisionality and thus the thermalization time in the high density, high temperature core can significantly differ from the average values used in global analyses. Overall, the primary effect of outward diffusion of 
alpha particles will likely be to flatten the heating profile relative to the birth profile.

The large perturbations from equilibrium in all the cases considered here could affect the MHD stability and control of the plasma. If the fluctuations in plasma pressure profile and electron temperature become too large, the plasma will be driven to the chamber walls. The maximum allowable fluctuations from MHD considerations will then likely define the limits within which the particle source feedback must control the density.

\section{SUMMARY}

One-dimensional, space-time transport models are widely available and can be useful tools for examining the thermal stability of D-T burning tokamaks. The density related instabilities examined here are an example of the usefulness of a one-dimensional analysis. Important spatially dependent effects which limit the application of global stability analyses are automatically included in a one-dimensional simulation. The physical model used here is simplified and is meant to illustrate the general technique. The effect of impurities, neutral gas recycle, and various transport mechanisms can easily be examined with existing models. Several other physical mechanisms may affect the stability analysis but would require some model development. The transport of fast alphas during thermalization may have a significant impact on the heating profile in the plasma. Strong coupling between the particle source deposition profile (e.g., pellets or neutral gas) and the density and 
temperatures could add an additional space-dependent effect not examined here due to the lack of a specific fueling model.

The rasults for both the beam-driven TETR plasma and the ignited plasma in UWMAK-III are based on specific models for particle and energy transport and thus are limited by the applicability of those models. The same general techniques can be used for other transport models. The density, temperature, and gradient dependence of the transport coefficients will play a role in the stability, as shown in the UWMAK-III results. For the trapped ion mode they all act together to exaggerate the thermal instability.

If the transport models prove to be realistic, several important conclusions can be made. The sensitivity of the equilibrium density in TETR to the particle source level indicates that such a source should at least have a tuning capability if feedback is not used. In UWMAK-III, feedback would be essential. Even though the instability develops a strong spatial dependence as it gets far from equilibrium, feedback on the average density can control the instability near equilibrium. The relatively long time scale for the instability to develop does not place a very high demand on the feedback system.

\section{ACKNOWLEDGMENTS}

This research was performed at the University of Wisconsin and supported by the Wisconsin Electric Utilities Research Foundation and by the U.S. Department of Energy under Contract No. ET-76-S-02-2272. The manuscript was prepared by the Oak Ridge National Laboratory, operated by Union Carbide Corporation for the U.S. Department of Energy under Contract No. W-7405-eng-26. 
TABLE I. PARAMETERS FOR TETR

Major radius

Minor radius in midplane

Plasma elongation

Toroidal magnetic field

Toroidal current

Neutral beam energy $\left(D^{\circ}\right)$

Neutral beam power

$$
\begin{aligned}
\mathrm{R} & =3.24 \mathrm{~m} \\
\mathrm{a} & =0.60 \mathrm{~m} \\
\mathrm{~b} / \mathrm{a} & =1.6 \\
\mathrm{~B}_{\mathrm{T}} & =4.19 \mathrm{~T} \\
\mathrm{I} & =2.52 \times 10^{6} \mathrm{~A} \\
\mathrm{E}_{\mathrm{O}} & =150 \mathrm{keV} \\
\mathrm{P}_{\mathrm{b}} & =150 \mathrm{MW}
\end{aligned}
$$


TABLE II. EQUILIBRIUM PARAMETIRS AND PERTURBATIONS FROM EQUILIERILIM FOR TETR CASES

\begin{tabular}{|c|c|c|c|c|c|c|}
\hline \multirow{2}{*}{ Parameter } & \multicolumn{3}{|c|}{ Corresponding to Fig. 1} & \multicolumn{3}{|c|}{ Corresponding to Fig. 2} \\
\hline & At equilibrium & At $200 \mathrm{~ms}$ & $(\%)$ & At equilitrium & At $200 \mathrm{~ms}$ & $(\%)$ \\
\hline $\bar{n}_{i}\left(\mathrm{~cm}^{-3}\right)$ & $7.500 \times 10^{13}$ & $7.498 \times 10^{13}$ & $(-0.27)$ & $7.500 \times 1.0^{13}$ & $7.495 \times 10^{13}$ & $(-0.67)$ \\
\hline$\overline{\mathrm{T}}_{\mathrm{e}}(\mathrm{keV})$ & 7.406 & $7.3 \div 3$ & $(-0.85)$ & 7.730 & 7.734 & $(+0.52)$ \\
\hline$\overline{\mathrm{S}}_{\mathrm{p}}\left(\mathrm{cm}^{-} \mathrm{ms}^{-1}\right)$ & $1.879 \times 10^{12}$ & $1.834 \times 10^{12}$ & $(-2.39)$ & $2.645 \times 10^{12}$ & $2.586 \times 10^{12}$ & $(-2.23)$ \\
\hline$\overline{\mathrm{s}}_{\mathrm{tot}}\left(\mathrm{cm}^{-3} \mathrm{~ms}^{-1}\right)$ & $2.032 \times 10^{12}$ & $1.936 \times 10^{12}$ & $(-2.26)$ & $2.797 \times 10^{12}$ & $2.738 \times 10^{12}$ & $(-2.11)$ \\
\hline$\tau_{p o}(m s)$ & 37.0 & & & 26.8 & & \\
\hline
\end{tabular}


TABLE III. PARAMETERS FOR UWMAK-III

$\begin{array}{lrl}\text { Major radius } & \mathrm{R} & =8.10 \mathrm{~m} \\ \text { Minor radius in midplane } & \mathrm{a} & =2.70 \mathrm{~m} \\ \text { Plasma elongation } & \mathrm{b} / \mathrm{a} & =2.0 \\ \text { Toroidal magnetic field } & \mathrm{B}_{\mathrm{T}} & =4.05 \mathrm{~T} \\ \text { Toroidal current } & \mathrm{I} & =15.8 \times 10^{6} \mathrm{~A}\end{array}$




\section{REFERENCES}

[1] STACEY, W.M., Jr., Nuc1. Fusion 15 (1975) 63.

[2] MILLS, R.G., "The Problem of Control of Thermonuclear Reactors," paper B1 in Engineering Problems of Fusion Research (Proc. Symposium Los Alamos, 1969), Los Alamos Scientific Laboratory Report LA-4250 (1969).

[3] OHTA, M., YAMATO, H., MORI, S., "lhermal Instability and control of Fusion Reactor," in Plasma Physics and Controlled Nuclear Fusion Research (Proc. 4th IAEA Conf. Madison, 1971) $\underline{3}$, IAEA, Vienna (1971) 423.

[4] BADGER, B., ABDOU, M.A., BOOM, R.W., BROWN, R.G., CHENG, T.E., CONN, R.W., DONHOWE, J.M., EL-GUEBALY, L.A., EMMERT, G.A., HOPKINS, G.R., HOULBERG, W.A., JOHNSON, A.B., KAMPERSCHROER, J.H., KLEIN, D., KULCINSKI; G.L., LOT̃T, R.G., McALEES, D.G., MAYNARD, C.W., MENSE, A.T., NEIL, G.R., NORMAN, E., SANGER, P.A., STEWART, W.E., SUNG, T., SVIATOSLAVSKY, I., SZE, D.K., VOGELSANG, W.F., WITLENBERG, L.J., YANG, T.F., YOUNG, W.C., University of Wisconsin Fusion Design Memo UWFDM-68, University of Wisconsin, Madison (1974).

[5] STACEY, W.M., Jr., Nucl. Fusion 13 (1973) 843.

[6] FUJISAWA, T., Nuc1. Fusion 14 (1974) 173.

[7] YaMATO, H., OHTA, M., MORI, S., Nucl, Fusion 12 (1972) 604.

[8] ROSENBLUTH, M.N., ROSS, D.W., KOSTOMAROV, D.P., Nuc1. Fusion 12 (1972) 3.

[9] HOGAN, J.T., "Multifluid Tokamak 'lransport Mode1s," in Methods in Computational Physics, Vol. 16 (KILlEEN, J., ALDER, B., FERNBACK, S., Eds.), Academic Press, New York (1976) 131. 
[10] DÜCHS, D.F., POST, D.E., RUTHERFORD, P.H., Nuc1. Fusion 17 (1977) 565 .

[11] HOGAN, J.T., Nuc1. Sci. Eng. 64 (1977) 2.

[12] HOUlbERG, W.A., CONN, R.W., Nuc1. Sci. Eng. 64 (1977) 141.

[13] KULCINSKI, G.L., CONN, R.W., MAYNARD, C.W., AUDENAERDE, K., AVCI, H., BLACKFIELD, D. , BOOM, R.W., CHENG, E., CONRAD, J.R. DALHED, H.E., EMMERT, G.A., FEINBERG, B., GOHAR, Y., HONG, S., KESNER, J., LARSEN, E., NYGREN, R., OKULA, K., RAMER, E., SCHARER, J., SCHLUDERBERG, D., SUNG, T., SVIATOSLAVSKY, I., SZE, D.K., VOGELSANG, W.F., WILKES, P., WILKES, W.R., WITLENBERG, L., WRAZEL, J., WU, T., YANG, T., YoUNG, W.C., (Note Vol I. p. 73 of proceedings), "TETR - A Tokamak Engineering Test Reactor ...," in Proc. 2nd ANS Topical Meeting on Technology of Controlled Nuclear Fusion (Richland, Washington, 1977), U.S. Department of Energy, CONF-760935 (1977).

[14] CONN, R.W., KULCINSKI, G.L., MAYNARD, C.W., ARONSTEIN, R., BOOM, R.W., BOWLES, A., CLEMMER, R.G., DAVIS, J., EMMERT, G.A., GHOSE, S., GOHAR, Y., KESNER, J., KUO, S., LARSEN, E., SCHAVER, J., SVIATOSLAUSKY, I., SZE, D.K., VOGELSANG, W.F., YANG, T.F., YOUNG, W.C'., "A High Performance Noncircular Tokamak Power Reactor Design Study - UWMAK-III," in Plasma Physics and Controlled Nuclear Fusion Research (Proc. 6th IAEA Conf. Berchtesgaden; 1976) $\underline{3}$, IAEA, Vienna (1977) 203.

[15] APGAR, E., COPPI, B., GONDHALEKAR, A., HELAVA, H., KOMM, D., MARTIN, F., MONTGOMERY, B., PAPPAS, D., PARKER, R., OVERSKEI, D., "HighDensity and Collisional Plasma Regimes in The Alcator Programme," in Plasma Physics and Controlled Nuclear Fusion Research (Proc. 6th IAEA Conf. Berchtesgaden, 1976) 1, IAEA, Vienna (1977) 247. 
[16] BUTLER, S.T., BUCKINGHAM, M.J., Phys. Rev. 126 (1962) 1.

[17] McAleES, D.G., CONN, R.W., Nucl. Fusion 14 (1974) 419.

[18] DAWSON, J.M., FURTH, H.P., TENNEY, F.H., Phys. Rev. Lett. 26 (1971) 1156.

[19] HiNTON, F.l., HAZELTINE, R.D., Rev. Mod. Phys. 48 (1976) 239.

[20] TSUJI, H., KATSUARAI, M., SEKIGUCHI, T., NAKANO, N., Nuc1. Fusion 16 (1976) 287 . 
FIGURE CAPTIONS

Fig. 1. Average density, $\bar{n}(t)$, and ion temperature, $\bar{T}_{i}(t)$, for a beamdriven plasma with trapped particle transport, a centrally peaked particle source profile, and instantaneous thermalization of the fusion alphas.

Fig. 2. Average density and ion temperature for a beam-driven plasma with trapped particle transport, a spatially uniform particle source profile, and instantaneous thermalization of the fusion alphas.

Fig. 3. Average density and ion temperature for a beam-driven plasma with trapped particle transport, a centrally peaked particle source profile, and finite thermalization time for the fusion alphas.

Fig. 4. Average density and ion temperature for a beam-driven plasma with trapped particle transport, a spatially uniform particle source profile, and finite thermalization time for the fusion alphas.

Fig. 5. Average density and ion temperature for a beam-driven plasma with anomalous transport $(D \sim 1 / n)$. The fastest varying case corresponds to a $0.36 \%$ perturbation in the equilibrium particle source.

Fig. 6. Average density and ion temperature for an ignited plasma with trapped particle transport, a centrally peaked particle source profile, and instantaneous thermalization of the fusion alphas. The particle source feedback is turned off at 4.5 and $5.4 \mathrm{~s}$. 
Fig. 7. Evolution of the density (a), electron temperature (b), and ion temperature (c) profiles for the model shown in Fig. 6 after the feedback is turned off at $4.5 \mathrm{~s}$.

Fig. 8. Evolution of the density profile for the model shown in Fig. 6 after the feedback is turned off at $5.4 \mathrm{~s}$.

Fig. 9. Average density and ion temperature for an ignited plasma with trapped particle transport, a spatially uniform particle source profile, and instantaneous thermalization of the fusion alphas. The particle source feedback is turned off at 4.5 and $5.4 \mathrm{~s}$.

Fig. 10. Evolution of the density (a) and ion temperature (b) profiles for the model shown in Fig. 9 after the feedback is turned off at $4.5 \mathrm{~s}$.

Fig. 11. Average density electron and ion temperatures for an ignited plasma with trapped particle transport, a spatially uniform particle source profile, and finite thermalization time for the fusion alphao. The characteristics of the instability dite changed by the finite thermalization timo only when the density is low and the thermalization time becomes long.

Fig. 12. Evolution of the density (a), electron temperature (b), and ion temperature (c) profiles for the case shown in Fig. 11. 
ORNL/OWG/FED 77-1026

TETR

INSTANTANEOUS ALPHA THERMALIZATION

TRAPPED PARTICLE TRANSPORT

$$
S_{p}(r, t)=S_{p}(t)(1-r / a)
$$

FEEDBACK ON

- - - FEEDBACK OFF AT $200 \mathrm{msec}$

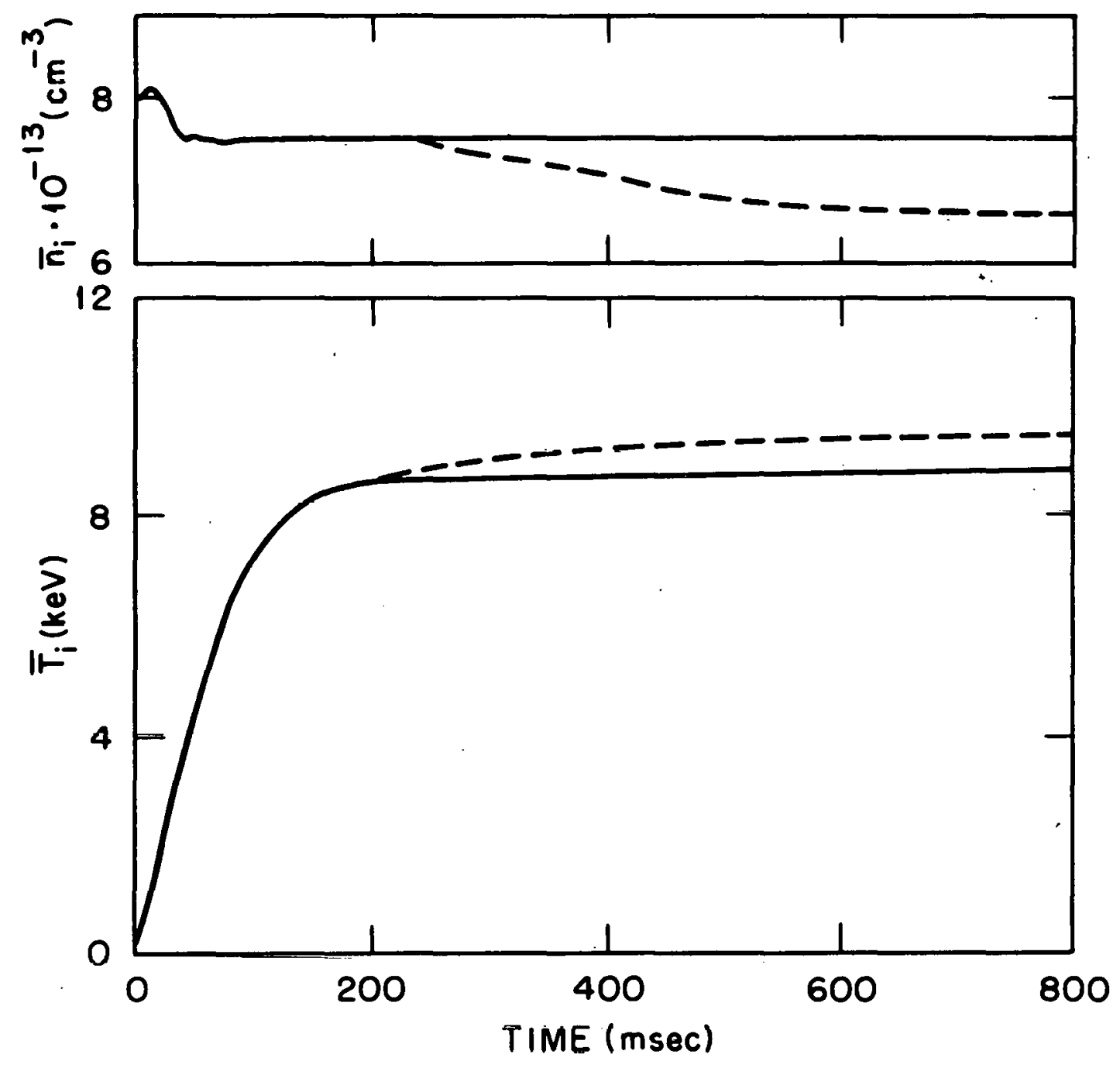

Fig. 1. 


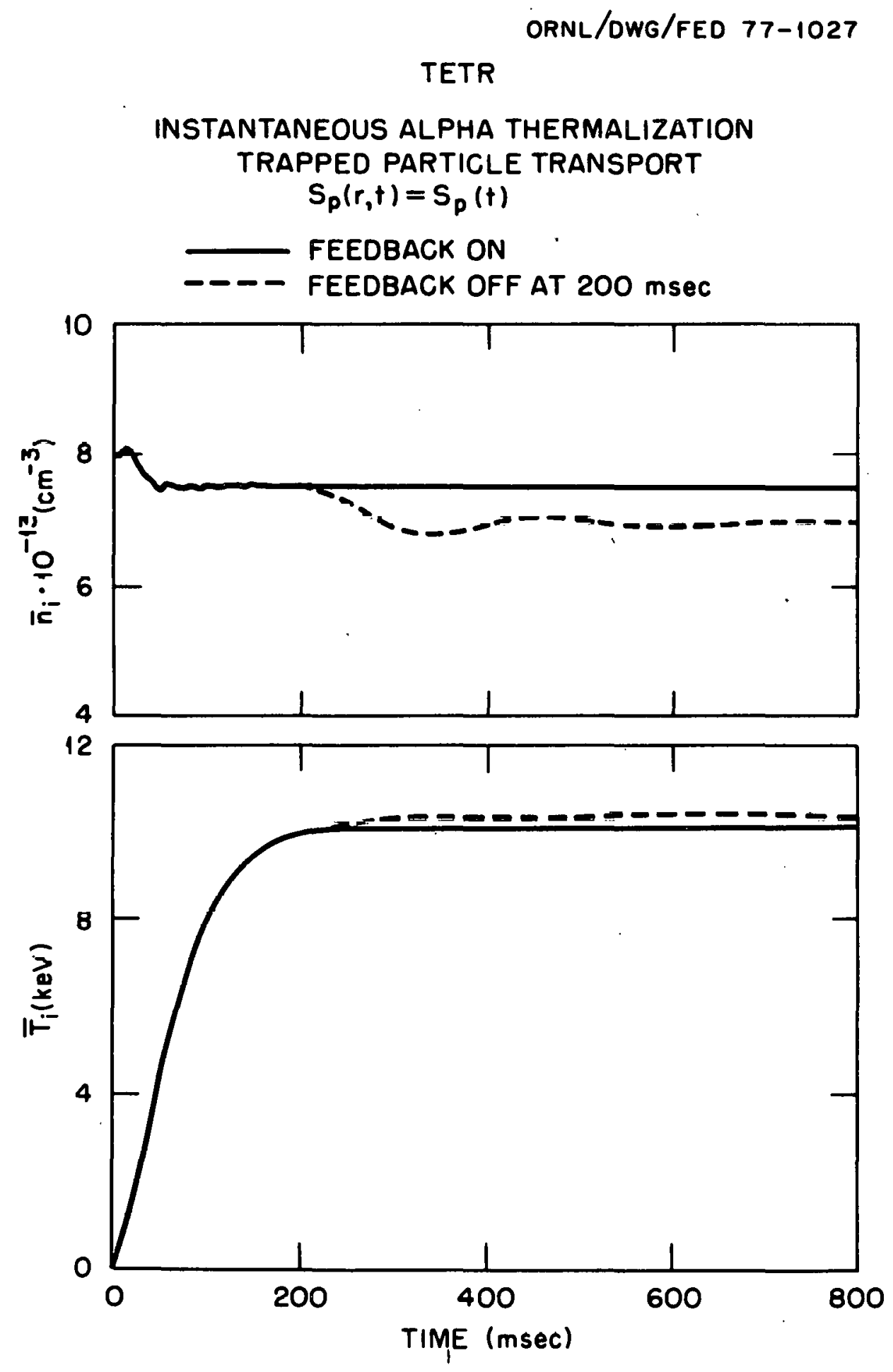

Fig. 2 , 


$$
\text { ORNL/DWG/FED 77-1028 }
$$

TETR

FINITE ALPHA THERMALIZATION

TRAPPED PARTICLE TRANSPORT

$$
S_{p}(r, t)=S_{p}(t)(1-r / a)
$$
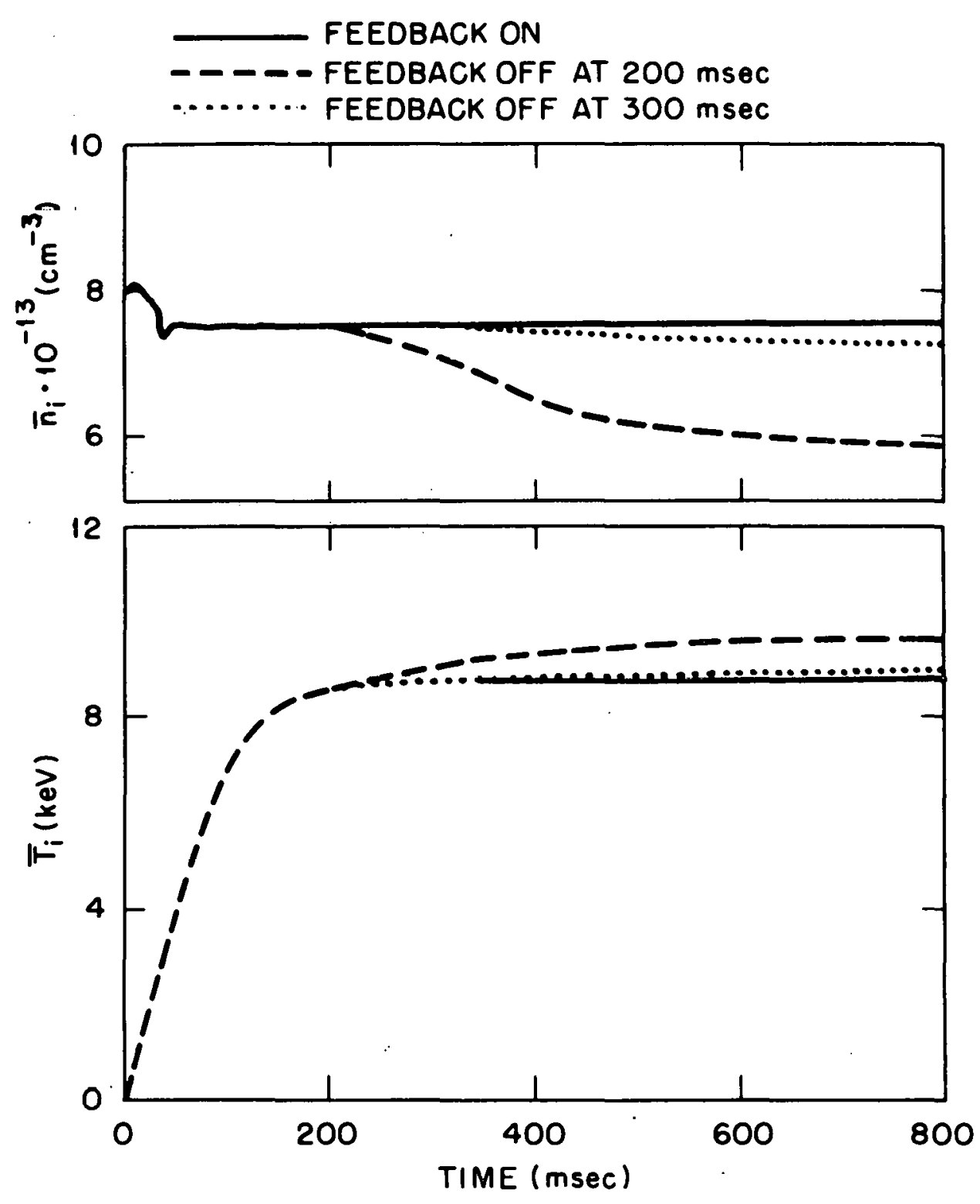

Fig. 3 . 


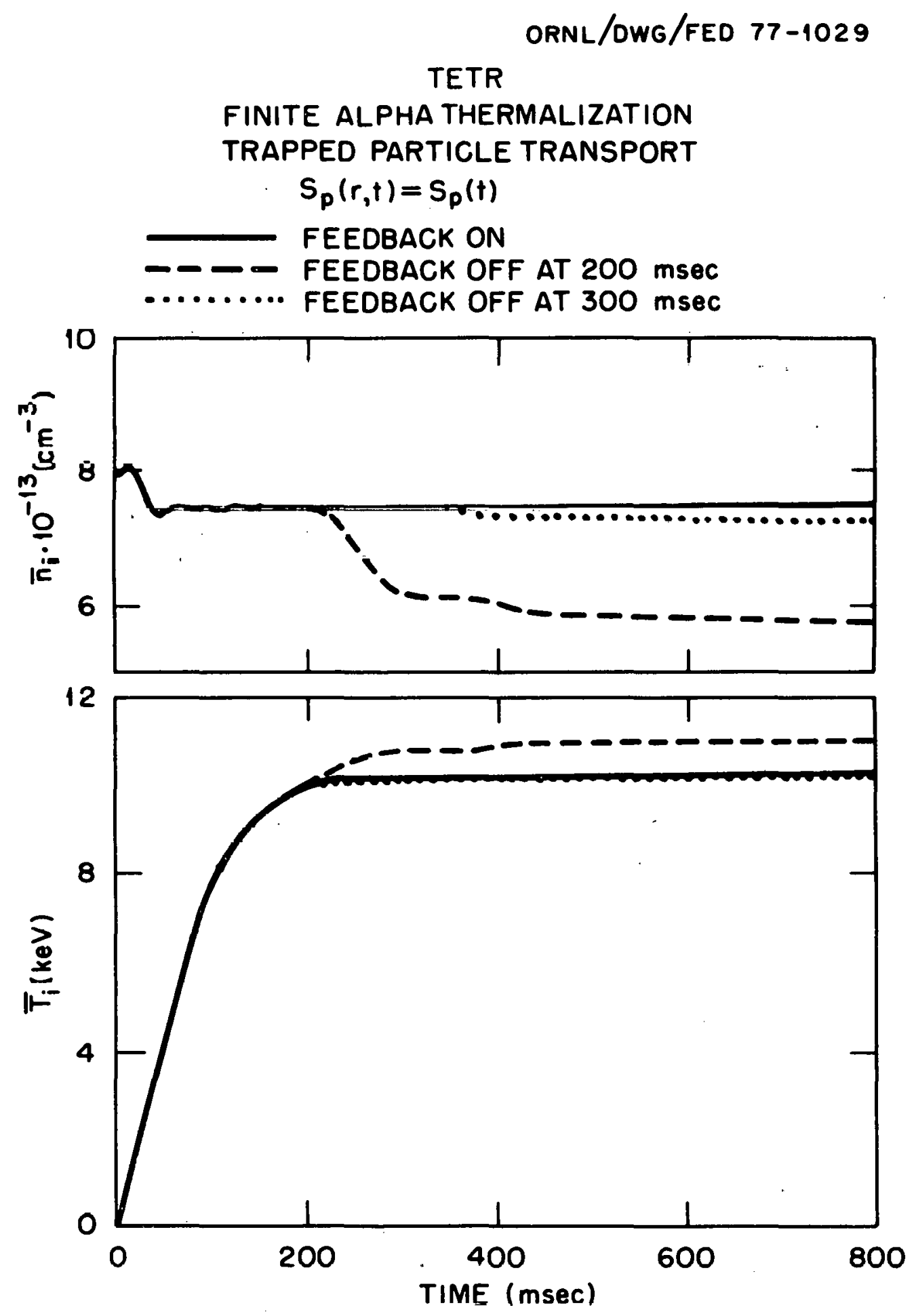

Fig. 4. 


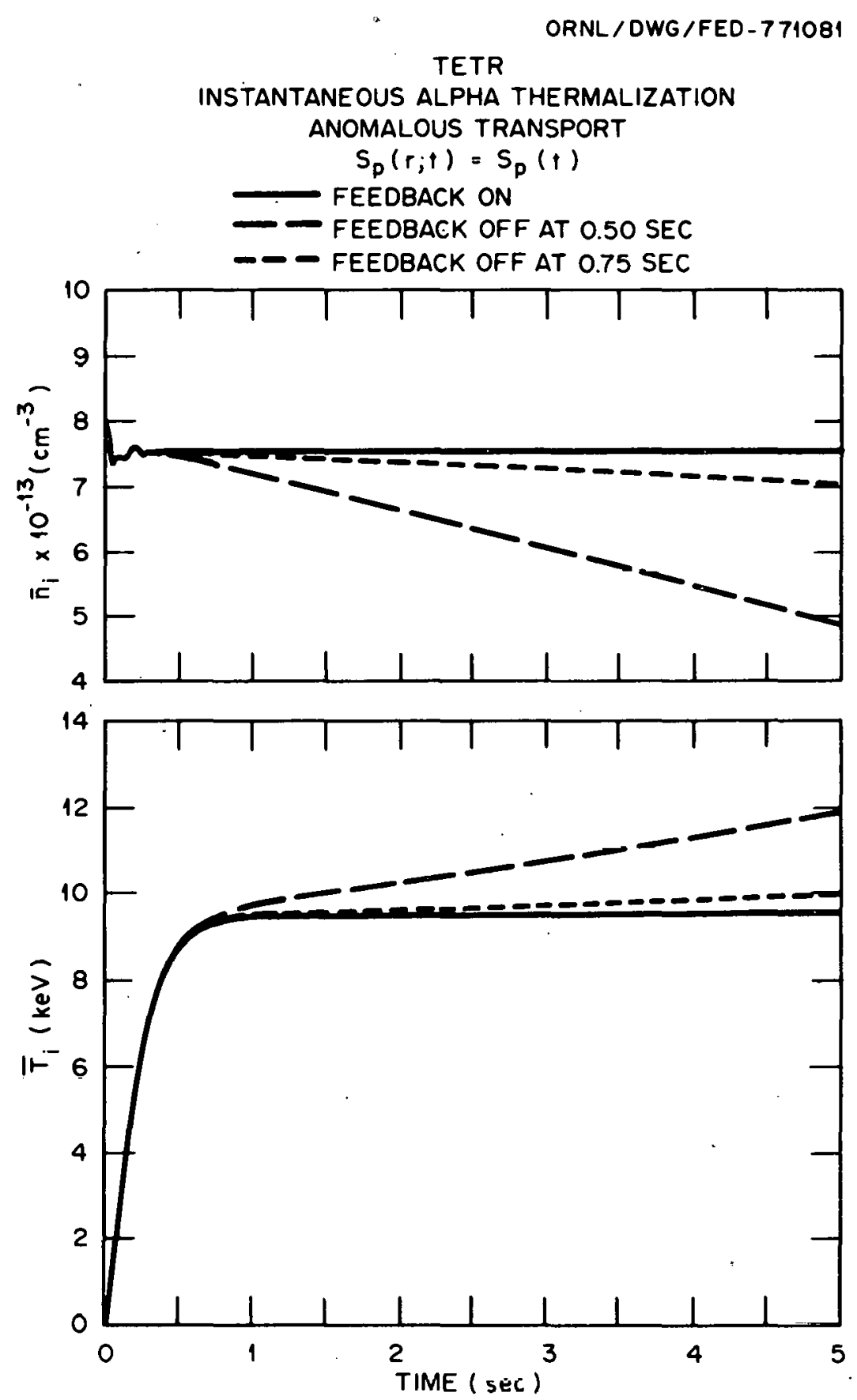

Fig. 5. 


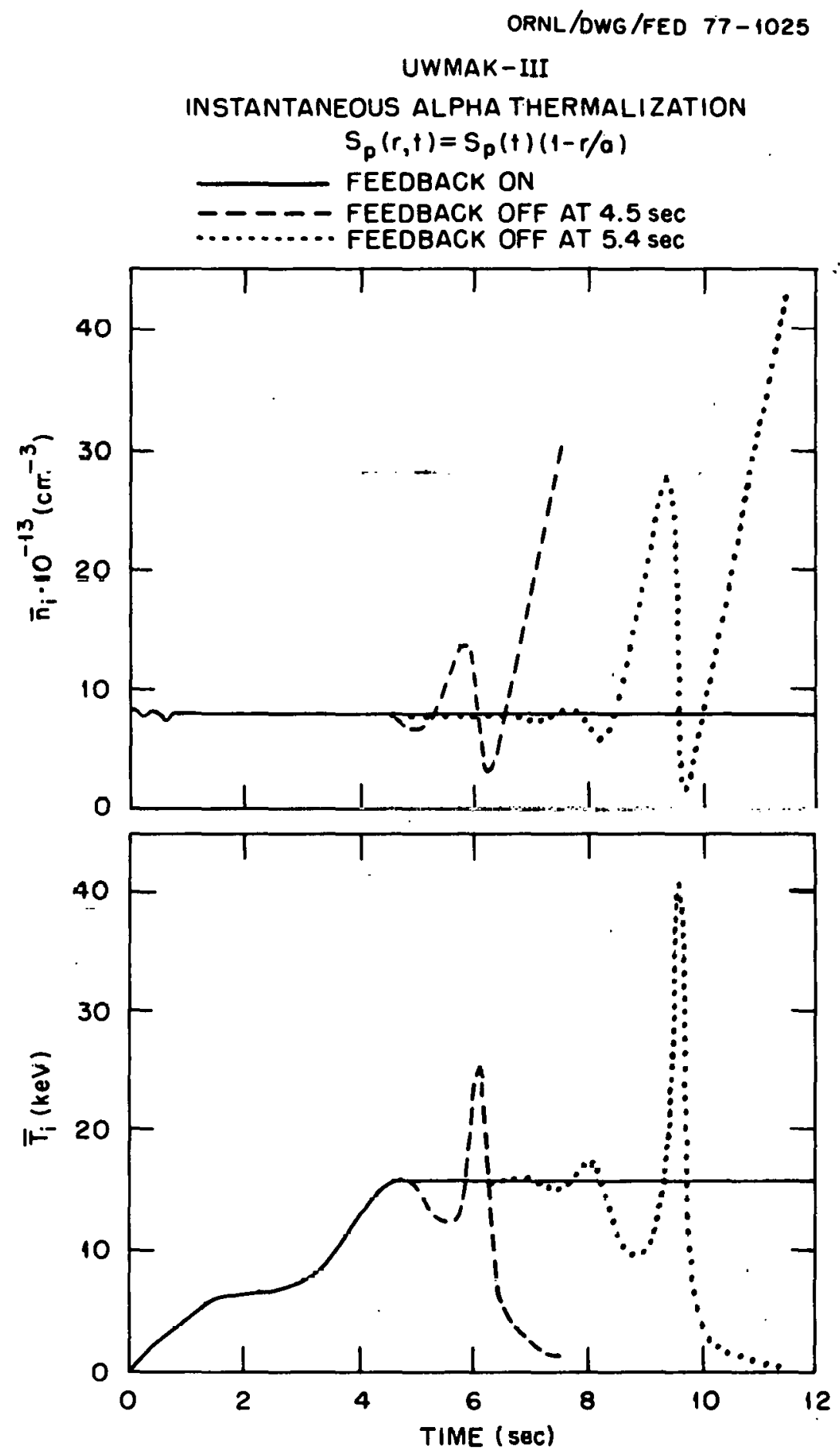

Fig. 6. 

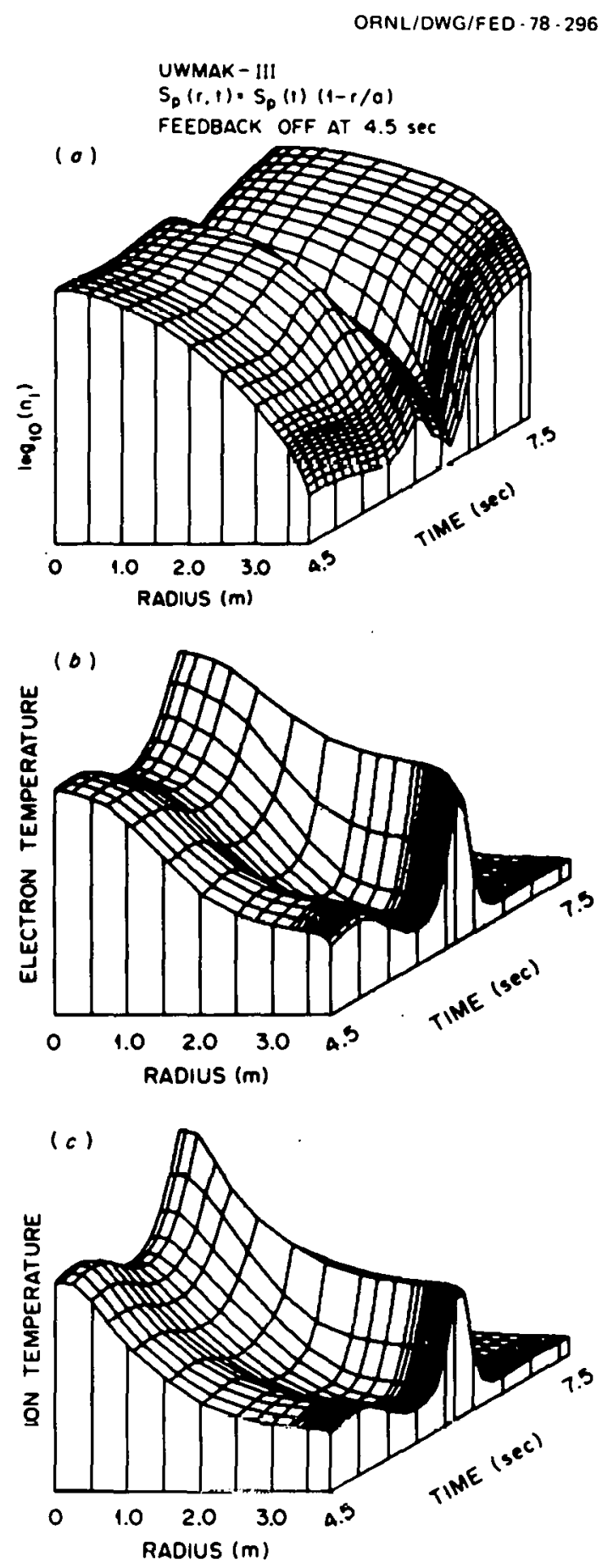

Fig. 7. 
ORNL/DWG/FED 77-1033

UWMAK - III

$S_{p}(r, t)=S_{p}(t)(1-r / a)$

FEEDBACK OFF AT $5.4 \mathrm{sec}$

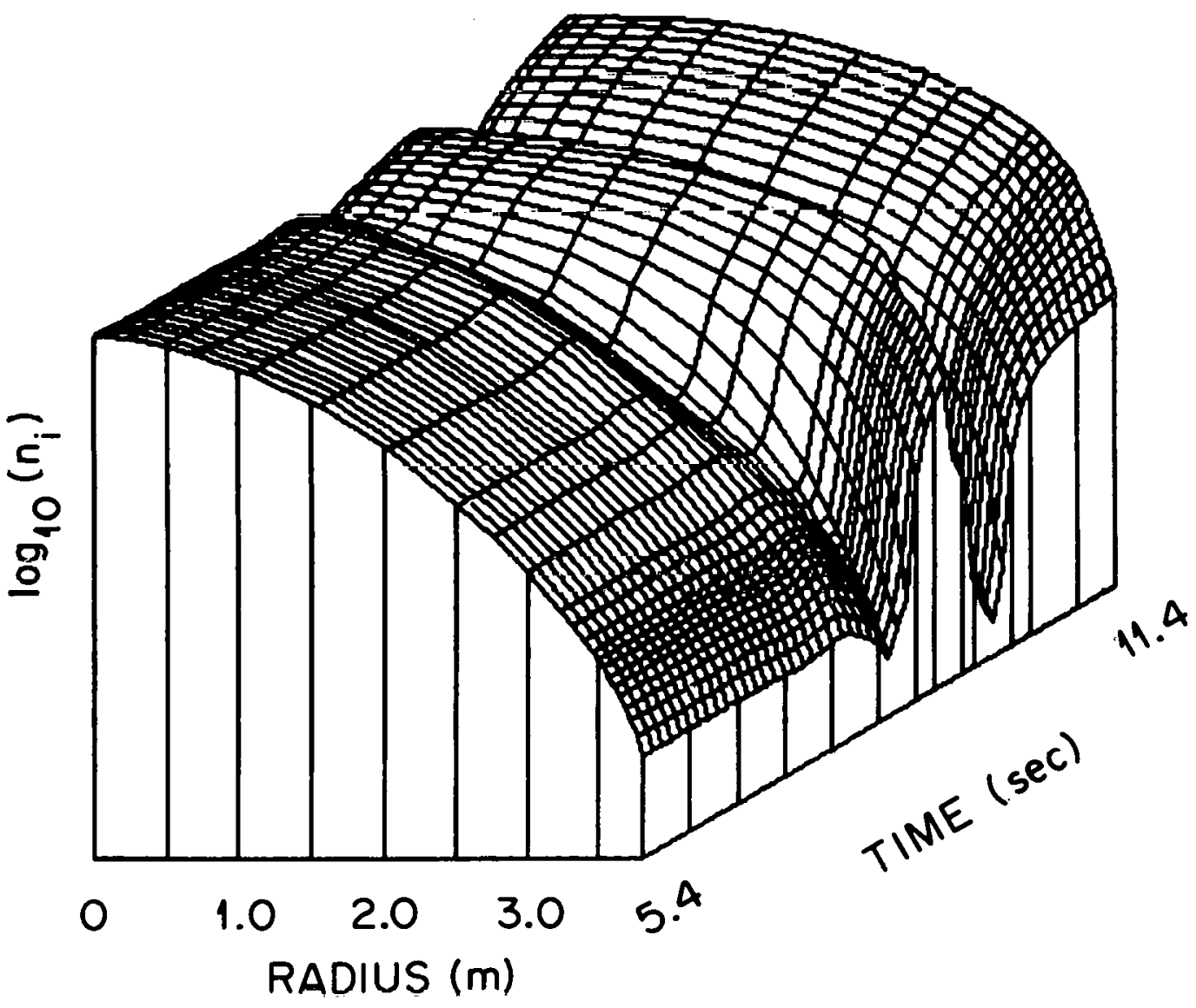

Fig. 8 . 


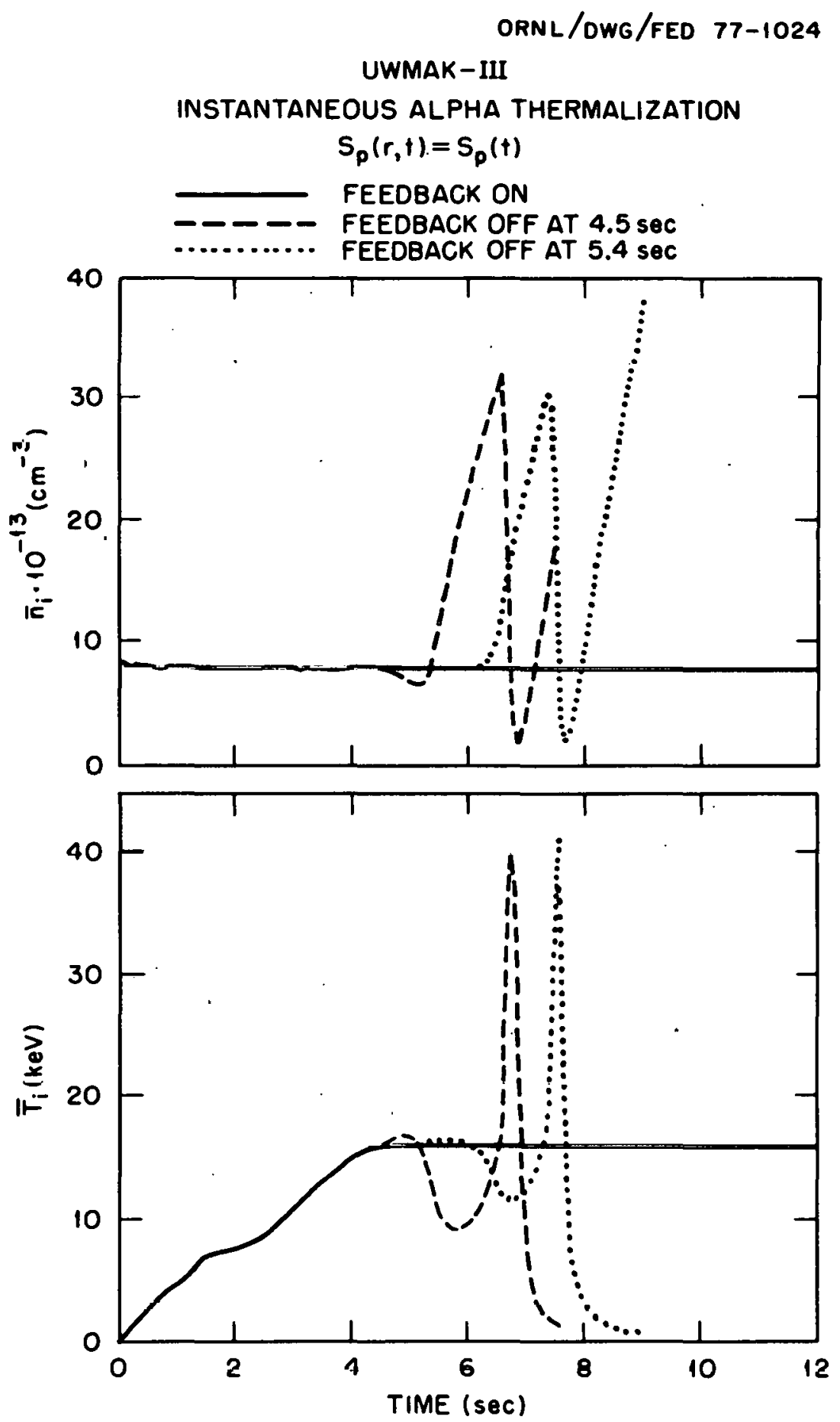

Fig. 9. 
ORNL/DWG/FED - 78 - 298
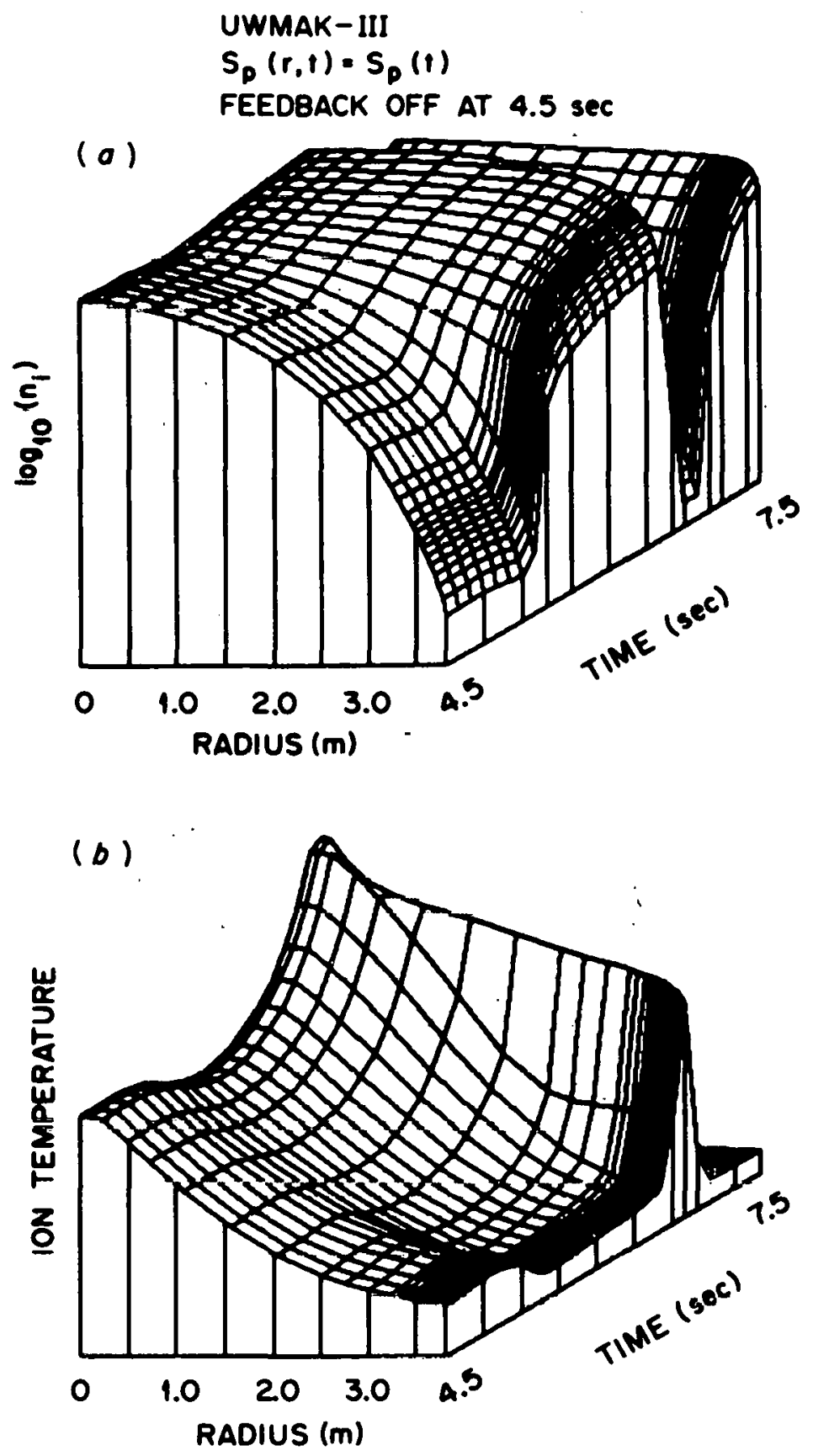

Fig. 10. 

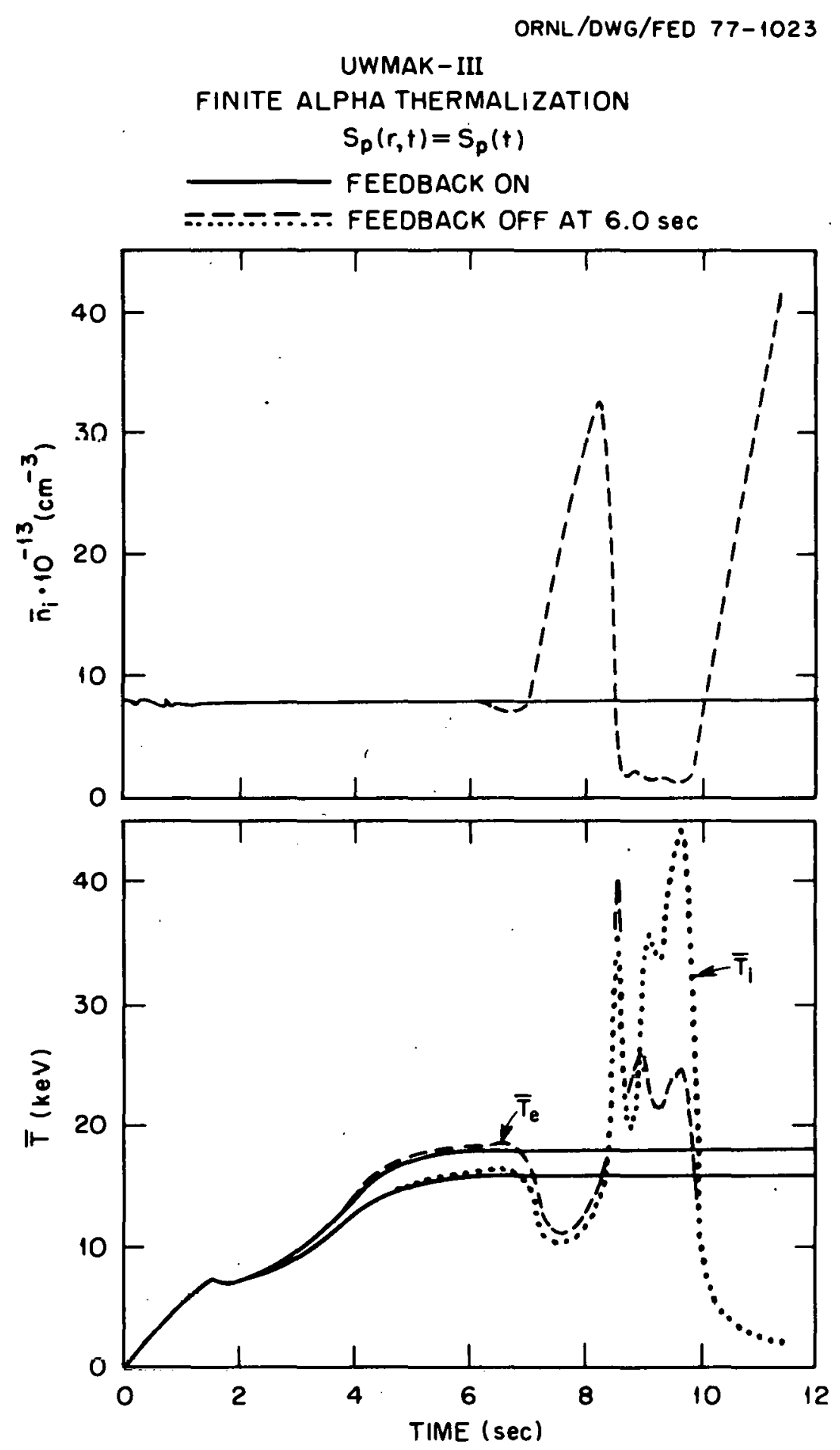

Fig. 11. 

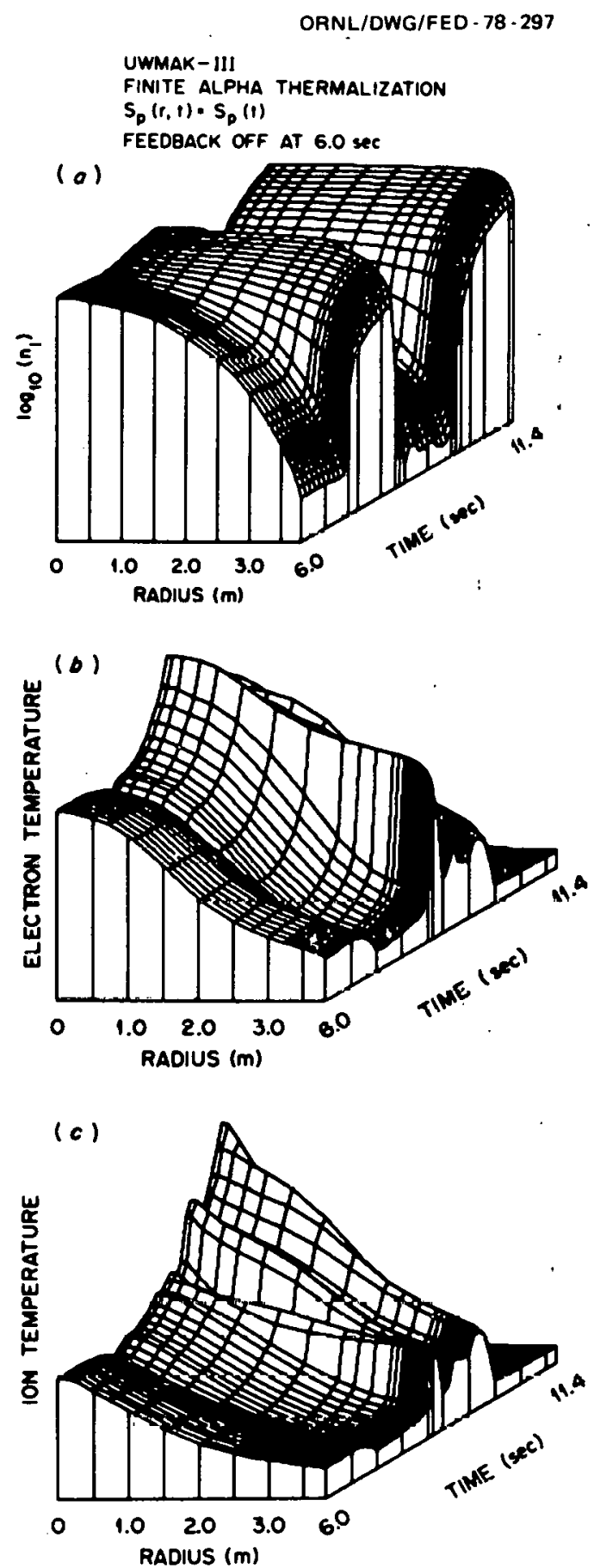

Fig. 12. 


\author{
ORNL/TM-6297 \\ Dist. Category UC-20a, d, and $\mathrm{g}$
}

\title{
INTERNAL DISTRIBUTION
}

\author{
1. L. A. Berry \\ 2. J. D. Callen \\ 3. R. A. Dandl \\ 4. R. A. Dory \\ 5. G. G. Kelley \\ 6. H. H. Haselton \\ 7. P. N. Haubenreich \\ 8. M. S. Lubell \\ 9. 0. B. Morgan \\ 10. H. Postma \\ 11. M. W. Rosenthal
}

\author{
12. J. Sheffield \\ 13. D. Steiner \\ 14-39. W. A. Houlberg \\ 40-41. Laboratory Records Department \\ 42. Laboratory Records, ORNL-RC \\ 43. Document Reference Section \\ 44-45. Central Research Library \\ 46. Fusion Energy Division Library \\ 47. Fusion Energy Division \\ Communications Center \\ 48. ORNL Patent office
}

\section{EXTERNAL DISTRIBUTION}

49. Bibliothek, Max-Planck Institute für Plasmaphysik, 8046 Garching bei Muinchen, Federal Republic of Germany

50. Bibliothèque, Service du Confinement des Plasmas, C.E.A., B.P. No. 6, 92, Fontenay-aux Roses (Seine), France

51. Lung Cheung, Department of Electronics, University Science Center, The Chinese University of Hong Kong, Shatin, N.T., Hong Kong

52. J. F. Clarke, Office of Fuston Energy, G-234, Department of Energy, Washington, DC 20545

53. D. Cohn, Massachusetts Institute of Technology, Cambridge, MA 02139

54. R. W. Conn, Fusion Technology Program, Nuclear Engineering Department, University of Wisconsin, Madison, WI 53706

55. CTR Library, c/o Alan F. Haught, United Technologies Research Laboratory, East Hartford, CT 06108

56. CTR Reading Room, c/o Allan N. Kaufman, Physics Department, University of Calitornia, Berkeley, CA 94720

57. Hatice Cullingford, office of Fusion Energy, G-234, Department of Energy, Washington, DC 20545

58. J. Narl Davidson, School of Nuclear Engineering, Georgia Institute of Technology, Atlanta, GA 30332

59. Documentation S.I.G.N., Départment de la Physique du Plasma et de la Fusion Controlée, Association EURATOM-CEA sur la Fusion, Centre d'Études Nucléa1res, B.P. 85, Centre du TKI, 38041 Grenoble, Cedex, France

60. W. R. El1is, Office of Fusion Energy, G-234, Department of Energy, Washington, DC 20545

61. G. A. Emmert, Nuclear Engineering Department, University of Wisconsin, Madison, WI 53706

62. Harold K. Forsen, Exxon Nuclear Co., Inc., 777 106th Avenue, N.E., C-000777, Bellevue, WA 98009 
63. Harold P. Furth, Princeton Plasma Physics Laboratory, Princeton University, Forrestal Campus, P.0. Box 451, Princeton, NJ 08540

64. Roy W. Gould, California Institute of Technology, Mail Stop 116-81, Pasadena, CA 91125

65. Charles R. Head, Office of Fusion Energy, G-234, Department of Energy, Washington, DC 20545

66. Robert L. Hirsch, Exxon Research and Engineering, P.0. Box 101, Florham Park, NJ 07932

67. Raymond A. Huse, Manager, Research and Development, Public Service Gas and Electric Company, 80 Park Place, Newark, NJ 07101

68. T. Hsu, Office of Fusion Energy, G-234, Department of Energy, Washington, DC 20545

69. V. E. Ivanov, Phyeical-Technical Tnstitute of the Ukranian Academy of Sciences, Sukhumi, U.S.S.R.

70. D. L. Jassby, Princeton Plasma Physics Laboratory, P.0. Bux 4j1, Princeton, NJ 08540

71. A. Kadish, Office of Fusion Energy, G-234, Department of Energy, Washington, IC 20545

72. L. M. Kovrizhnikh, Lebedev Institute of Physics, Academy of Sciences of the U.S.S.R., Leninsky Prospect 53, Moscow, U.E.S.R.

73. Guy Laval, Groupe de Physique Théorique, Ecole Polytechnique, 91 Palaiseau, Paris, France

74. Library, Centre de Recherches en Physique des Plasma, 21 Avenue des Bains, 1007, Lausanne, Switzerland

75. Library, Culham Laboratory, United Kingdom Atomic Energy Authority, Abingdon, Oxon, 0x14 3DB, United Kingdom

76. Library, FOM-Institut voor Plasma - Fysica, Rijnhuizen, Jutphaas, Netherlands

77. Library, Institute for Plasma Physics, Nagoya University, Nagoya, Japan 464

78. Library, International Centre for Theoretical Physics, Trieste, Italy

79. Library, Laboratorio Gas Ionizzati, Frascati, Italy

80. Dsumber G. Lominadze, Academy of Sciences of the Georgian S.S.R., 8 Dzerzhinski St., 38004, Tbilisi, U.S.S.R.

81. Oscar P. Manley, Office of Fusion Energy, G-234, Department of Energy, Washington, DC 20545

82. D. G. McAlees, Exxon Nuclear Co., Inc., Research and Technology Laser Enrichment Department, 2955 George Washington Way, Richland, WA 99352

83. J. E. McCune, School of Engineering, Department of Aeronaur1cs and Astronautics, Bldg. 37-391, Massachusetés Injtitute uf Technology, Cambridge, MA 02139

84. Claude Mercier, Service du Theorie des Plasmas, Centre d'Études Nucléaires, Fontenay-aux-Roses (Seine), France

85. K. G. Moses, Office of Fusion Energy, G-234, Department of Energy, Washington, DC 20545

86. Michael Murphy, Office of Fusion Energy, G-234, Department of Energy, Washington, DC 20545 
87. D. Pfirsch, Institute for Plasma Physics, 8046 Garching bei München, Federal Republic of Germany

88. Plasma Physics Group, Department of Engineering Physics, Australian National University, P.0. Box 4, Canberra A.C.T. 2600, Australia

89. Robert E. Price, Office of Fusion Energy, G-234, Department of Energy, Washington, DC 20545

90. A. Rogister, Institute for Plasma Physics, KFA, Postfach 1913, D-5170, Jülich 1, Federal Republic of Germany

91. W. Sadowski, Office of Fusion Energy, G-234, Department of Energy, Washington, DC 20545

92. V. D. Shafranov, I. V. Kurchatov Institute of Atomic Energy, 46 Ulitsa Kurchatova, P.0. Box 3402, Moscow, U.S.S.R.

93. Yu. S. Sigov, Institute of Applied Mathematics of the U.S.S.R. Academy of Sciences, Miuskaya, Sq. 4, Moscow A-47, U.S.S.R.

94. W. M. Stacey, Jr., School of Nuclear Engineering, Georgia Institute of Technology, Atlanta. GA 30332

95. L. D. Stewart, Princeton Plasma Physics Laboratory, P.0. Box 451, Princeton, NJ 08540

96. J. B. Taylor, Culham Laboratory, U.K. Atomic Energy, Authority, Abingdon, Oxon, OX14 3DB, United Kingdom

97. Thermonuclear Library, Japan Atomic Energy Research Institute, Tokai, Naka, Ibaraki, Japan

98. Francisco Verdaguer, Director, Division of Fusion, Junta de Energia Nuclear, Madrid 3, Spain

99. K. M. Zwilsky, Office of Fusion Energy, G-234, Department of Energy, Washington, DC 20545

100. Director, Research and Technical Support Division, Department of Energy, Oak Ridge Operations, P.O. Box E, Oak Ridge, TN 37830

101-335. Given distribution as shown in TID-4500, Magnetic Fusion Energy (Distribution Category UC-20a, d, and g: Plasma Systems, Fusion Systems, and Theoretical Plasma Physics) 